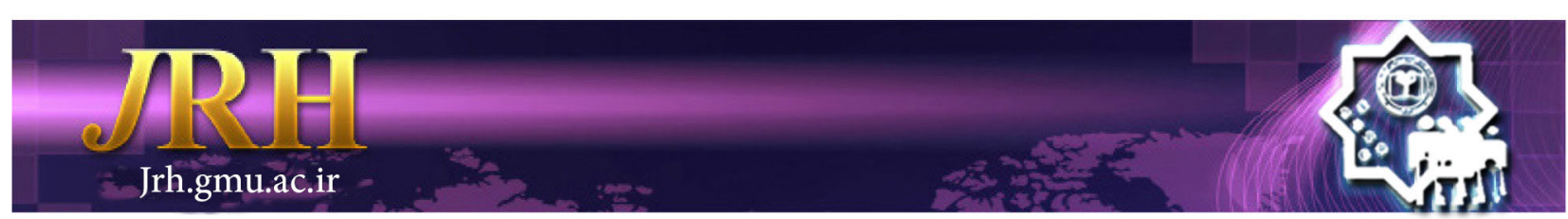

\title{
The effective sociological factors on body modification among Tehranian women
}

\author{
Mitra Sarabian ${ }^{1}$, Dariush Boostani ${ }^{2}$
}

\author{
Journal of Research \& Health \\ Social Development \& Health Promotion \\ Research Center \\ Vol. 8, No. 3, May \& Jun 2018 \\ Pages: 262- 268 \\ DOI: $10.29252 / j r h .8 .3 .262$ \\ Original Article \\ 1. Department of Sociology, Faculty of \\ Literature and Humanity, Sciences and Research \\ University, Tehran, Iran \\ 2. Correspondence to: Department of Social \\ Sciences, Faculty of Literature and Humanity, \\ Shahid Bahonar University of Kerman, Kerman, \\ Email: dboostani@uk.ac.ir
} Iran

Received: 23 Feb 2016

Accepted: 14 Dec 2016

How to cite this article: Sarabian M, Boostani D. The effective sociological factors on body modification among Tehranian women. $J$ Research Health2018; 8(3): 262- 268.

\begin{abstract}
Body is center of many debates in sociology during last decades. Sociologists believe that human body is a project of identity. It seems that women pay more attention to their body; therefore, this study investigated the effective factors on body modification of Tehranian women. Body modification includes weight control, cosmetic services, using medicines and creams, and medical services. Among the theories of body modification, theories of Pierre Bourdieu, Anthony Giddens, and Brayan Turner were selected as the theoretical framework of this research; then research model and hypothesis were extracted. The statistical population was all of the Tehranian women at the age range of 22-44 years. Using multi-stage cluster sampling method, 384 women were selected. A researcher-made questionnaire was used for data collection. The results of the study showed that body modification can have a significant relationship with consumerism, media consumption, personal identity, social class and age. Moreover, nearly $47 \%$ of body modification changes were explained by "consumerism", 7\% by "media consumption", and $12 \%$ by "personal identity". The results showed that the age group of 25-35 years has the highest practice of body modification. Furthermore, "social class" showed a positive significant relationship with body modification. According to the theories of Giddens, Bourdieu and Turner, it can be concluded that modernity and its components consumerism, hegemony of media, and identification influences the body modification of Tehranian women.
\end{abstract}

Keywords: Modification, Consumption, Identity, Women

\section{Introduction}

In recent years, human body has been studied as an important subject by sociologists. The importance of body has been shown both in empirical research and sociological theorization [1]. The previous studies [2-7] showed that humans have formed their bodies through different methods, including a wide range of traditional methods such as food control and neck lift or modern ways like cosmetic surgeries. Accordingly, Body modification means actions such as weight control, cosmetic services, using medicines and creams, and medical services. Sociologists have conceptualized body as a 'project' that is worked on and transformed as a central part of self-identity [2]. It's been accepted in sociology that the body is a central picture we have from ourselves [8,9]. In the modern society, women and girls are exposed to the bombard of standard social messages and body size [10]. Women have much more 
dissatisfaction with body than men. This is because of normative pressure and object-like outlook on body in consuming and capitalist societies. Women are often the subject of gazing. So, they go on a regime or do a plastic surgery or experience nutritive disorders with a higher probability [11].

There are some factors showing the necessity and significance of a research, including its scientific problem, its relation to a big or influential population and filling the gap of previous studies [12]. Over-sensitivity to body and its appearance has led to problems such as nourishment disorder, confidence decrease, thinness, physical injuries, etc. [13]. This sensitivity is higher in women and young girls in comparison to men [8, 13-19].

The results of Swami's [20] study demonstrated a meaningful difference between beauty ideals and body dissatisfaction in different regions. Age, body mass index, and western media predicted the ideal weight. Tiggemann and Ruutel [14] found that women under less influence of Western-American culture (Estonia) experience less body dissatisfaction. Moreover, gender differences were observed in these two countries and women experienced more body dissatisfaction and desired to lose weight. Study of Rezaei et al., [21] indicated a meaningful relationship between body management and factors such as consumerism, social pressure, and media consumption. Zokai et al., [19] indicated that selecting the surgery has been an attempt at reaching individual satisfaction.

Previous studies indicated that media consumption, socio-economic class, gaining status features and confidence, and the effect of international cultural pressures through mass media are among the special values of the forms and sizes of the ideal body which are effective on the behavior of people. The role of media in inspiring the ideal image of the body and the tendency to correct and manipulate attitude and its relationship with nutritive disorders and social pressures are effective on individuals' tendency to reach the specified standards.

Measuring body modification is important practically and theoretically. The present study is also practical and through understanding effective variables on body modification, the results can be used in policy making and planning for mass media and advertisement for these products to improve the status quo and help resolving the current and future problems.

According to the theoretical discussion of the study, the theoretical framework of this study has been drawn based on the theories of Pierre Bourdieu, Anthony Giddens, and Bryan Turner.

According to Bourdieu [22], the people's appearance shows their social position more than their personal character; also personality and clothing are not separated from each other and people's clothing have been considered as an indication of their social class or professional character. In our time, fashions and clothing modes have been under the influence of pressure groups, advertisements, socio-economic factors, and the other factors that promote mandatory standards more than the individual differences. One of the most important factors in today's life style is perhaps the influence of mass media, especially TV (Television) [22]. Capitalism based on consumption, with efforts to equalizing the consumption and shape the tastes of the people through advertising, plays a key role in promoting self-infatuation. The idea of creation of a well-trained community has been finished against waves of pervasive consumerism since a long time ago. Under the consuming-conditions, the society is dominated by appearances [22].

Pierre Bourdieu considers the physical capital as one of the cultural sub-capital, and a type of cultural source which has been invested into the body [23]. He believes that the physical capital in the social shaping of the body using the activities is in accordance with individuals' class position and considers the relationship between everyone and his body as one of the fundamental aspects of the class character [23].

Turner [24] believes that project of the body is a lifelong project that may have a need 
to be managed and maintained. Focus on maintenance and "body project" in the Western interpretation (post-modernity) at the time of mass consumption, He considers the body as a project which has become a permanent process that is considered to be a flexible entity; and constantly being renovated. Turner [25] believes that the contemporary scientific interest should be regarded as a response to fundamental changes in the relationship between the body and economy, simulation technology, and society. Scientific advances, especially reproductive technologies and therapeutic simulations have encountered the body with some problems. The emphasis on consumerism has caused more attention to pleasure as a result of changes in the perception of the body. He believes that the contemporary anxiety about diet and obesity on the body lead to development of the rational accounts on body and application of knowledge in the social system of control [25]. Turner [25] believes that the idea of creating a body has been appeared by medical technology providing plastic surgery, cosmetic, dentistry, etc.

Measuring body modification is important both practically and theoretically. The present study is also practical and through understanding effective variables on body modification. Factors that indicate necessity of this research were as follows: studying the women as half of the population of the society; high sensitivity of body among women than men; the relevance of body modification strategies to the health practices; the absence of independent variable such as personal identity in previous studies, and non-consideration of social class as a multidimensional variable in literature.

The results of current research can be used in policy making and planning for mass media and advertisement to improve the status quo and help resolving the current and future problems. This study was attempted to primarily investigate the role of economic, cultural, and social factors on body modification and secondly to explore its effective factors on such behavioral, consuming choice, increasing emphasis on diets and the responsibility for body fitness among Tehranian women.

\section{Method}

The present study was a quantitative study utilizing survey method. A closed questionnaire was applied for data collection. The modifying variables mentioned on the questionnaire were of two kinds: dependent variable included weight control, cosmetic services, using medicines, creams, and medical-cosmetic services and independent variables consisted of age(three age group), consumerism; social class (three categories), media consumption, and personal identity.

The study population were all 20-40 years old women in Tehran $(\mathrm{N}=1,838,455)$ in 2014. Since the framework of sampling was not specified and statistical population was to some extent heterogeneous, multi-stage cluster sampling was used. Accordingly, 22 areas were divided into low, mid, and high class based on socio-economic situations. Then, 10 areas were selected from these three main areas which were $1,2,3,4,5,6,12$, $26,27,28$. In this sampling, first a sample is selected among the areas followed by sampling from big areas. Then, some areas are sampled from smaller ones. Finally, the families and their members are selected [29]. The sample size was estimated 384 women Lin [30] table regarding 50\% parameter, 95\% confidence level, and 5\% error level.

Numerous theoretical studies have been done for designing this questionnaire and gaining construct validity. The face validity of this questionnaire has been verified by experts. To consider the face validity, the questionnaire was piloted to compensate for the problems such as ambiguity, inappropriate order and lengthiness of the questionnaire. Ten experts from sociology department were asked about the probable problems of each scale.

The Cronbach' alpha coefficients were higher than 0.70 (Body modification $=0.93$; Consumerism $=0.92$; personal identity $=0.70$; median consumption $=0.70$ ) indicating the reliability of the scales $(n=35)$.

The data were analyzed using SPSS-16 and runningdescriptive and inferential statistics. The significant level was set as 0.05 in inferential 
statistics. The techniques were selected based on the level of variable measurement.

\section{Results}

Hypothesis 1: There is a signification relationship between consumerism and body modification. To probe the relationship between consumerism and body modification, linear regression was run.

As shown in Table 1, there is a relationship between consumerism and body modification regarding coefficient of correlation (0.68). Based on determination coefficient which is $\mathrm{R}^{2}=0.47$, it can be said that nearly $47 \%$ of body modification changes is explained by consumerism.

Table 1 Consumerism and body modification

\begin{tabular}{lccccc}
\hline Statistics model & $\begin{array}{c}\text { Regression } \\
\text { coefficient }\end{array}$ & Standard error & Standardized beta & $\mathrm{T}$ & Sig \\
\hline Constant & 33.257 & 3.086 & - & 10.776 & 0.001 \\
Consumerism & 1.817 & 0.099 & 0.683 & 18.292 & 0.001 \\
\hline
\end{tabular}

Hypothesis 2: There is a significant relationship between media consumption and body modification.

As it is clear from Table 2, there is a relationship between media consumption and body modification. Coefficient of correlation between them is 0.27 and considering determination coefficient which is $\mathrm{R}^{2}=0.07$, it can be said that nearly $7 \%$ of body modification changes is explained by media consumption.

Table 2 Media consumption and body modification

\begin{tabular}{lccccc}
\hline Statistics model & $\begin{array}{c}\text { Regression } \\
\text { coefficient }\end{array}$ & $\begin{array}{c}\text { Standard } \\
\text { error }\end{array}$ & $\begin{array}{c}\text { Standardized } \\
\text { Beta }\end{array}$ & T & Sig \\
\hline Constant & 56.449 & 5.575 & - & 10.122 & 0.001 \\
Media consumption & 1.769 & 0.314 & 0.272 & 6315. & 0.001 \\
\hline
\end{tabular}

As shown in the Table 3, there is a relationship between personal identity and body modification. Coefficient of correlation between them was 0.34 and regarding determination coefficient which is $\mathrm{R}^{2}=0.12$, it can be said that nearly $12 \%$ of body modification changes is explained by personal identity.

Table 3 Personal identity and body modification

\begin{tabular}{lccccc}
\hline Statistics model & $\begin{array}{c}\text { Regression } \\
\text { coefficient }\end{array}$ & Standard error & Standardized Beta & T & Sig \\
\hline Constant & 19926. & 8.482 & - & 3.089 & 0.002 \\
Personal identity & 4401. & 1990. & 3480. & 2517. & 0.001 \\
\hline
\end{tabular}

Hypothesis 4: There is a significant relationship between social class and body modification.

The results of Chi-showed a significant relationship between social class and body modification ( $p=46.85)$. The result of KendallTau-c correlation (tau-c $=0.29$ ) showed a weak relationship between the social class and body modification. So, it can be said that in higher social class, body modification increases slightly.
Hypothesis 3: There is a significant relationship between personal identity and body modification.

Hypothesis 5: There is a significantrelationship between age and body modification.

The result of ANOVA test demonstrated a significant difference between attitude and body modification across different ages. Moreover, the results of Tuckey test indicated that mean score of the group aged 25-35 had significant difference with the other age groups. 
Table 4 Social class and body modification

\begin{tabular}{ccccc}
\hline \multirow{2}{*}{ Social class } & High & Mid & Low \\
Bodymodification & & & \\
\hline Low & $\mathrm{F}$ & 12 & 52 & 21 \\
\cline { 2 - 5 } & $\%$ & 13.04 & 21.67 & 40.38 \\
\hline Mid & $\mathrm{F}$ & 38 & 135 & 27 \\
\cline { 2 - 5 } & $\%$ & 41.3 & 56.25 & 51.92 \\
\hline High & $\mathrm{F}$ & 42 & 53 & 4 \\
\cline { 2 - 5 } Total & $\%$ & 45.65 & 22.08 & 7.69 \\
\cline { 2 - 5 } & $\%$ & 92 & 240 & 52 \\
\hline $\begin{array}{c}\text { Chi Square- } 64.86 \\
\text { Kendall tau-C }=.293\end{array}$ & & 100 & 100 \\
\hline
\end{tabular}

Table 5 Age and body modification

\begin{tabular}{|c|c|c|c|c|c|c|c|c|}
\hline \multirow{2}{*}{ Variable } & \multirow[b]{2}{*}{ Age } & \multirow[b]{2}{*}{$\mathrm{F}$} & \multirow[b]{2}{*}{ Mean } & \multirow[b]{2}{*}{ SD } & \multicolumn{2}{|c|}{ Mean square } & \multirow[b]{2}{*}{$\mathrm{F}$} & \multirow[b]{2}{*}{ Sig } \\
\hline & & & & & $\begin{array}{l}\text { Between } \\
\text { group }\end{array}$ & Within group & & \\
\hline \multirow{3}{*}{ Body modification } & Less than 25 & 82 & 85.30 & 21.71 & \multirow{3}{*}{2895.104} & \multirow{3}{*}{609.583} & \multirow{3}{*}{4.75} & \multirow{3}{*}{0.009} \\
\hline & 25-35 year & 182 & 91.02 & 26.14 & & & & \\
\hline & More than 35 & 120 & 82.33 & 24.30 & & & & \\
\hline
\end{tabular}

\section{Discussion}

According to Giddens, Turner, and Bourdieu, it can be said that the opportunities for changing the body in consuming culture are abundant and consumption culture has changed the body project into an activity among all members of society. The opportunity given to individuals by media has provided new opportunities for people's socio-economic status. According to the results of this study, consumerism, personal identity, and media explained 46\%, $12 \%$, and $7 \%$ of the changes of body modification, respectively. The higher the social class, the more body modification was done. Moreover, most of body modifications were done in the group aged 25-35 years old.

The results revealed a relationship between body modification and consumerism concerning coefficients of correlation (0.68) and consumerism explained $46 \%$ of body modification changes. In other words, consumerism was in relationship with fashion and people try to appropriate their body with the fashions.
The opportunities for manipulating the body in consumerism are abundant which can led to disappearance of natural understanding of the body [32]. Rezaei et al., [21] and Luo [6] also showed significant relationships between the body management and consumption.

Our second hypothesis on the relationship between body modification and media consumption was accepted with respect to obtained correlation coefficient $(0.22)$. The media consumption explained $7 \%$ of the changes of body modification indicating that media such as satellite, TV, and magazines had a significant role in body modification.

Through globalization of mass media, the performance of different organizations in various fields are believed to open new choices for people. The sticking effect of TV and newspapers by juxtaposing various opportunities and states create special forms and symbols insinuating new choices [22]. Rezaei [21] and Swami [20] indicated a significant relationship between media 
consumption and body management that is consistent with our findings.

The third hypothesis on a significant relationship between body modification and personal identity was also supported by achieving correlation coefficient of 0.348 . Personal identity explained about $12 \%$ of body modification changes.

Giddens [32] noted the experience of people about the concept of the "self" and "identity" in the modern era. He believes that the "self' and "body" are under the influence of the modern era which is distinguished by specifying the reflexivity in traditional society. He believes that the people in this era are reflexive about their social system, their life conditions, their future and the self which is culminated in changing their environment.

The fourth hypothesis on the relationship between body modification and social class was also supported showing a weak strength of relationship. The higher the social class, , the body modification was more. In fact, those with higher social class possess more opportunities for body modification because consumption opportunities are not given to individuals equally and depends on socioeconomic capital.

Bourdieu [23] believes that the social context of all reactions is the system of interests and preferences which forms the behavior of a class and considered everybody's relation with his/her body as a fundamental dimension of class system. So, one side is the instrumental relationship with the body shown by labor class in all behaviors and the other side is the tendency of high social class considering body as an innate goal [23]. Similarly, Swami[20] indicated that social class is accompanied with high dissatisfaction with body and the tendency to thinness.

The last research hypothesis was on a significant relationship between different ages and body modification. Tuckey post-hoc test showed that the highest and lowest body modification happened in 25-35 years age group and $<35$ years age group, respectively. Currently, age social group is clearly a social structure. The issue of age is considerably different in all cultures and societies [31]. Two main limits of the research was dispersion of areas and refusion of some participants to interview.

\section{Conclusion}

According to Giddens, one of the identity factors of individuals is appearance. The people restore their identity in appearance and face where they represent themselves. In current societies, people work on their bodies through consuming behaviors. The media are the source of advertisements and beauty promulgating unnecessary needs among women for making a different identity. Women with buying different kinds of clothes and other cosmetic products try to fit their bodies and have an appearance in line with the standards. Media advertisements have a significant effect on the tendency of the society toward consumerism and some moves to body modification. Especially consumerism is in relationship with fashion. These people receive the messages or resist against them to be indifferent or act according to them. The advertisement can influence the health of society members. The media cause these extremist behaviors. So, attention to planning, warning the risks of exorbitant use of these products and ads seem necessary.

\section{Acknowledgments}

We express our sincere appreciation to Tehranian women who participated in this study.

\section{Contribution}

Study design: DB, MS

Data collection and analysis: MS, DB

Manuscript preparation and edition: DB, MS

\section{Conflict of Interest}

"The authors declare that they have no competing interests."

\section{Funding}

The authors received financial support for this research from Jiroft University of Medical Sciences. 


\section{References}

1- Howson A, Inglis D. The body in sociology: tensions inside and outside sociological thought. Soc Rev2001; 49(3): 297-317.

2- Shilling C. The body and social theory. London: Sage; 2012.

3- Gimlin D. Body work: Beauty and self-image in American culture. Berkeley, CA, USA: University of California press; 2001.

4- Turner BS. Regulating bodies: essays in medical sociology. USA \& Canada: Psychology press; 1992.

5- Grogan S, Wainwright N. Growing up in the culture of slenderness: girls' experiences of body dissatisfaction.

Women Stud Intr Forum1996; 19(6): 665-73.

6- Luo W. Aching for the modern body: chinese Women's Consumption of Cosmetic Surgery. 2008; [2screens]. Available at https:/www.deepdyve.com/lp/elsevier/ aching-for-the-altered-body-beauty-economy-andchinese-women-s-wdQxDJI9Ct. Accessed March 1, 2013.

7- Choi PM. Looking good and feeling good: Why do fewer women than men exercise. In Ussher J, ed. Women's health: contemporary international perspectives. Leicester: BPS (British Psychological Society) Book; 2000. pp: 373-7.

8- Featherstone M. Postmodernism and consumer culture. London: Sage; 1991.

9- Goffman E. Behavior in public places: notes on the social organization of gathering. New York: The free press; 1963.

10- Hargreaves D, Tiggemann M. The effect of "thin ideal" television commercials on body dissatisfaction and schema activation during early adolescence. $J$ Youth Adolesc2003; 32(5): 367-73.

11- Grogan S. Body image: understanding body dissatisfaction in men, women and children. USA \& Canada: Routledge; 2007.

12- Miller MN, Pumariega AJ. Culture and eating disorders: a historical and cross-cultural review. Psychiatry2001; 64(2): 93-110.

13- Khajenoori B, Moghadas AA. An investigation of relationship between globalization and body image, case study: Tehran, Persian in Shiraz \& Estahbān. Journal of Applied Sociology2009; 20(1): 1-24.

14- Tiggemann M, Ruutel E. A cross-cultural comparison of body dissatisfaction in Estonian and Australian young adults and its relationship with media exposure. J Cross Cult Psychol2001; 32(6): 736-42.

15- Glazer RN. Women's body image and the law. Duke Law J1993; 43(1): 113-47.

16- Johansson T. Gendered spaces: The gym culture and the construction of gender. Young Uppsala1996; 4(3): $32-47$.

17- Azad Armaki T, Chavoshian H. The body as a medium of identity. Iranian Journal of Iranian $s$ Sociology2003; 4(4): 57-75.

18- Keyvanara M, Ghorbani M, Jiyanpour M. Social grouping and body improvement: cosmetic surgery as symbol of social base. Women's Strategic Studies2010; 12(47): 73-98.

19- Zokai M. Farzane H. Body language and culture, selected fields of cosmetic surgery in women. Cultural and Communication Studies2008; 4(11): 45-61.

20- Swami V, Frederick DA, Aavik T, et al. The attractive female body weight and female body dissatisfaction in 26 countries across 10 world regions: results of the international body project I. Pers Soc Psychol Bull2010; 36(3): 309-25.

21- Rezaei A, Inalu M, Fekri M. Body management and its relationship with social factors among female students of Mazandaran University. Women's Strategic Studies2010; 12(47): 141-70.

22- Bourdieu P. Cultural theory: an anthology. United Kingdom:Wiley-Blackwell; 2011.

23- Bourdieu P. Distinction: A social critique of the judgment of taste. America: Harvard University press; 1984.

24- Turner BS. The body: Social process and cultural theory. London: Sage; 1991.

25- Turner BS. The body and sociology: exploration in sociology theory. London: Sage; 1996.

26- Thompson KJ, Heinberg LJ. The media's influence on body image disturbance and eating disorders: We've reviled them, now can we rehabilitate them? J Soc Issues 1999; 55(2): 339-53.

27- Botta RA. For your health? The relationship between magazine reading and adolescents' body image and eating disturbances. Sex Roles2003; 48(9-10): 389-99.

28- Ahmadnia SH. Sociology of the body and the body of women. Women J2006; 5; 132-43.

29- De Vaus D. Surveys in social research. London: Rutledge; 2013.

30- Lin N. Foundation of social research. New York: McGraw Hill; 1979.

31- Aronson N. Comment on bryan turner's. The government of the body: medical regimens and the rationalization of diet. Br J Sociol1984; 35(1): 62-5.

32- Giddens A. Modernity and self-identity: Self and society in the late modern age. California: Stanford University press; 1991.

\footnotetext{
Copyright(C) 2016 ASP Ins. This open-access article is published under the terms of the Creative Commons Attribution-NonCommercial 4.0 International License which permits Share (copy and redistribute the material in any medium or format) and Adapt (remix, transform, and build upon the material) under the Attribution-NonCommercial terms.
} 